\title{
Assessing Perceptual Sensitivity of Respiratory Load Using Constant Airway Resistance
}

\section{Tom Powell ${ }^{1}$ and Edgar M Williams ${ }^{2 *}$}

${ }^{1}$ Cardiff School of Healthcare Sciences, Cardiff University, Cardiff, UK

${ }^{2}$ Faculty of Life Sciences and Education, University of South Wales, Pontypridd, UK

\begin{abstract}
Introduction: Breathlessness or dyspnoea is a complex subjective sensation that is an important feature of cardio-respiratory disease which is difficult to quantify. An objective measure would be useful as it would allow patients symptoms and response to therapy to be summarized and compared.
\end{abstract}

Objectives: This study aims to investigate whether a new approach could be used to quantify resistive load detection in participants with healthy lungs or obstructive lung disease with breathlessness.

Methods: Sixteen participants (five with chest disease, MRC dyspnoea score 4) were variously tested using three respiratory loading protocols, and applying a resistance between 0.2 to $1.5 \mathrm{kPa}$.L.sec ${ }^{-1}$.

Results: In a healthy group $(\mathrm{n}=11)$ a sigmoidal relationship between load detection and applied load was observed with the $50 \%$ detection rate being $0.5 \mathrm{kPa}$.L. $\mathrm{sec}^{-1}$ and a minimal load detection between 0.2 and $0.3 \mathrm{kPa}$. L. $\mathrm{sec}^{-1}$ whereas in the group with chest disease $(n=5)$ a threshold response was seen instead and a load below $0.75 \mathrm{kPa}^{2}$.. $\mathrm{sec}^{-1}$ was undetectable.

Conclusions: In health there is a graded response to extrathoracic resistive respiratory loading, with the perceptual sensitivity independent of the method of load delivery. In lung disease the perceptual sensitivity is lost and load detection is reported (all or nothing) only above a threshold $\left(0.75 \mathrm{kPa}\right.$.L. $\left.\mathrm{sec}^{-1}\right)$. This approach provides a simple method for quantifying resistive load detection.

Keywords: Load detection; COPD; Breathlessness; Dyspnoea

Abbreviations: COPD: Chronic Obstructive Disease; FEV ${ }^{1}$ : One Second Forced Expiratory Volume (L); RK: Constant Resistance

\section{Introduction}

Breathlessness is a complex subjective sensation that is a common symptom of cardio-respiratory disease, it is difficult to quantify but it is necessary to do so that patient reposnse to therapy can be assessed [1]. The subjective difficulty of distress in breathing is difficult to acurately quantify, yet breathlessness is closely linked to chest disease with airway obstruction, and is therefore a common characteristic in patients. This can be due to permanent airway obstruction such as with COPD or recurrent reversible obstruction caused by airway hyperresponsiveness such as with asthma.

Accurate perception of changes in airway obstruction is a critical component in the self-management of chest disease and breathlessness is a common reason for referral for lung function assessment [2,3]. In healthy subjects quantification of the changes in mechanical load is a relatively simple task but this may be more difficult in diseases with airway obstruction. Typically $15-40 \%$ of adults with asthma fail to consistently recognise clinically significant breathing changes and better perceptual accuracy is associated with significantly less functional morbidity [4]. Failure to perceive symptoms of an oncoming asthma 'attack' has been suggested as one of the reasons for a delay in patients seeking treatments which can then lead to life-threatening events [5].

Historically the MRC dyspnoea scale has been used clinically for over fifty years to subjectively assess patients perception of disability associated with their breathlessness [6]. Other scales such the Borg or visual annual scales are used to quantify a patient's perception of their breathlessness [7]. These approaches while reliant on a patients perceptual ability have been extensively used as they as relatively cheap, simple and quick to use. The MRC dyspnoea scale can predict survival and is advocated as complementary to $\mathrm{FEV}^{1}$ in describing disability in those with COPD $[8,9]$.
While there is no direct method for measuring the sensation of dyspnoea, indirect techniques have been proposed using resistive loading $[2,5,10]$. While the advantage of this approach is that it allows a quantitative assessment of dyspnoea it presents an inherent difficulty in that the applied load is not constant and flow dependent. This study describes a new technique which uses a computer driven respiratory mouthpiece in which the resistive load can be held constant independently of the airflow rate. This ensures the load can be applied throughout the respiratory cycle.

The study aims to investigate if it is feasible to quantify differences in the perceptual sensitivity of different respiratory loads. An additional aim is to define the optimal protocol for a resistive load detection trial.

\section{Methods}

\section{Study participants}

Sixteen participants, five with chest disease (Table 1) were recruited into the study. Ethical approval was obtained from both the local NHS Research Ethics Committee and the Faculty Research Ethics committee. Written informed consent was secured for each participant before testing took place. Diagnosis of asthma or COPD in patients was confirmed from their medical notes. After completing dynamic lung function measurements participants undertook a series of resistive load detection trials.

*Corresponding author: Dr. Williams EM, Faculty of Life Sciences and Education University of South Wales, Pontypridd, CF37 1DL, UK, Tel: 44-1443-483963; E-mail: Mark.williams@southwales.ac.uk

Received December 12, 2014; Accepted January 22, 2015; Published January 26, 2015

Citation: Powell T, Williams EM (2015) Assessing Perceptual Sensitivity of Respiratory Load Using Constant Airway Resistance. J Pulm Respir Med 5: 236. doi:10.4172/2161-105X.1000236

Copyright: $\odot 2015$ Powell T, et al. This is an open-access article distributed under the terms of the Creative Commons Attribution License, which permits unrestricted use, distribution, and reproduction in any medium, provided the original author and source are credited. 


\begin{tabular}{|c|c|c|c|}
\hline & $\begin{array}{c}\text { Controls } \\
(n=11)\end{array}$ & $\begin{array}{c}\text { Asthma } \\
(n=2)\end{array}$ & $\begin{array}{c}\text { COPD } \\
(n=3)\end{array}$ \\
\hline Sex (M:F) & $11: 0$ & $2: 0$ & $2: 1$ \\
\hline Age $(\mathrm{yrs})^{* *}$ & $18-29$ & $40-51$ & $60-65$ \\
\hline FEV ${ }^{1 \% p r e d}$ pr $^{*}$ & $99 \pm 14$ & $93 \pm 13$ & $36 \pm 12$ \\
\hline MRC Dyspnoea Score** & $* * *$ & $1-2$ & $4-5$ \\
\hline
\end{tabular}

${ }^{*}$ Mean and SD are shown **range ***not recorded.

Table 1: Participant demographics.

\section{Materials}

The loading device consists of a pneumotachograph mouthpiece which contains a computer controlled variable orifice (MicroRMA, MicroMedical Ltd, Kent, UK) [11]. By measuring flow and mouth pressure, the device contiunally maintains airflow resistance by altering the internal diameter of the oriface via feedback at $100 \mathrm{~Hz}$. A constant resisitve load, $\mathrm{R}_{\mathrm{K}}$, is therefore maintained throughout the resting tidal respiratory cycle. The device was calibrated daily for flow using a three litre syringe and pressure by applying a $10 \mathrm{~cm} \mathrm{H}_{2} 0$ pressure using a water U-tube manometer. When the orifice was fully open and no bacterial filter added the resitance of the pneumotachograph was 0.14 $\mathrm{kPa} . \mathrm{L} / \mathrm{sec}$ at a flow of $1 \mathrm{Lmin}^{-1}$.

The $\mathrm{R}_{\mathrm{K}}$ device was then combined in series with an analogue digital converter (ADi Powerlab ADinstruments Ltd, Oxford, UK ) which included its own pneumotachograph, push button device and recording software (Chart5, ADinstruments Ltd, Oxford, UK) (Figure 1). The $R_{K}$ device was programmed to apply a load throughout quiet tidal breathing and when the participant detected a resistive load they were instructed to push the button. The response was recorded concurrently with the flow signal from the pneumotachograph, along with the resistance used (Figure 2). For all trials each participant breathed through the experimental set up via a mouthpiece and bacterial filter. All participants were seated and wore nose clips and had no prior experience of the device.

\section{Design}

An important aim was to use a protocol that allowed a detailed repeatable response but one that at the same time was not too onerous for the participants to complete, thus avoiding fatigue. A range of protocol parameters can to be set, for example the duration of the loaded phase (the number of breaths that the resistive load is applied for), the range of loading, the number of different loads, and how often they should be applied (or presented to the participant) and finally the number unloaded breaths between the loaded ones (Table 2).

A loaded two breath cycle was adopted, which was short enough to avoid changes in blood gas composition which could influence load detection sensitivity [10]. The $\mathrm{R}_{\mathrm{K}}$ device when used elsewhere used a minimum and maximum $\mathrm{R}_{\mathrm{K}}$ load of 0.15 and $1.5 \mathrm{kPa} . \mathrm{L}_{\mathrm{sec}} \mathrm{s}^{-1}$ respectively [11]. This range was shown to elicit a suitable response with the greatest

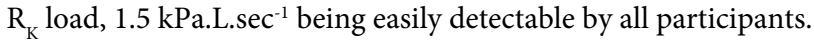

To obtain a graded response while not being unduly taxing on study participants, eight separate loads were selected, 1.5, 1.25, 1.0, $0.75,0.5,0.3,0.2$ and $0.15 \mathrm{kPa} . \mathrm{L} \cdot \mathrm{sec}^{-1}$ [11]. Two loading sequences were applied (descending and random) and repeated twice. Therefore each load was applied four times, once in each trial.

The unloaded period between each load application was set to vary between 3-8 breaths in a preset, non-systematic order to prevent temporal sequence detection. This same order was used for all participants to allow for comparison.
The effect of load delivery sequence was assessed using two protocols; in protocol A the participants received the loads in descending order from 1.5 to $0.15 \mathrm{kPa} . \mathrm{L} . \mathrm{sec}^{-1}$. This is similar to the British Audiological Society's guidelines that apply hearing tests in a descending fashion [12]. In Protocol B the loads were applied in a random order selected from a pre-prepared random list, with each participant given a different order.

\section{Instruction to participants}

Participants were given a demonstration trial of two breaths loaded at the highest RK that they would experience in the subsequent trials. They were shown how to depress the red push button when they thought a load had been applied. Previous studies have used a push button to signal load detection however not all followed the same instruction protocol. Davenport et al. asked participants to listen to music during the test [5]. This was necessary to mask any experimental equipment sounds. Several studies informed their participants with a signal light that a resistance was about to be applied $[2,4,13]$. Another study describes how the operator "stood behind a curtain and manipulated the apparatus quietly" so to give no indication to the subject when loads were applied [10]. The $\mathrm{R}_{\mathrm{K}}$ device makes some noise as the servomotor in the mouthpiece continually alters the internal diameter of the orifice. Therefore in the unloaded phases the device was set at an $\mathrm{R}_{\mathrm{K}}$ of $0.01 \mathrm{kPa} . \mathrm{L} \cdot \mathrm{sec}^{-1}$ so that the device would continue to make an operating sound, therefore avoiding extra noise for loaded breath.

The healthy participants undertook both protocols twice completing four trials in all on their initial visit. The patient group followed protocol A once. The healthy participants made a second visit undertaking the four trials each with eight $\mathrm{R}_{\mathrm{K}}$ loaded phases. This was followed by an additional trial, Protocol $\mathrm{C}$, in which each participant was given the loads at 1.0, 0.75, 0.5 and $0.25 \mathrm{kPa} . \mathrm{L}_{\mathrm{sec}}{ }^{-1}$, eight times so that the repeatability of detection could be ascertained.

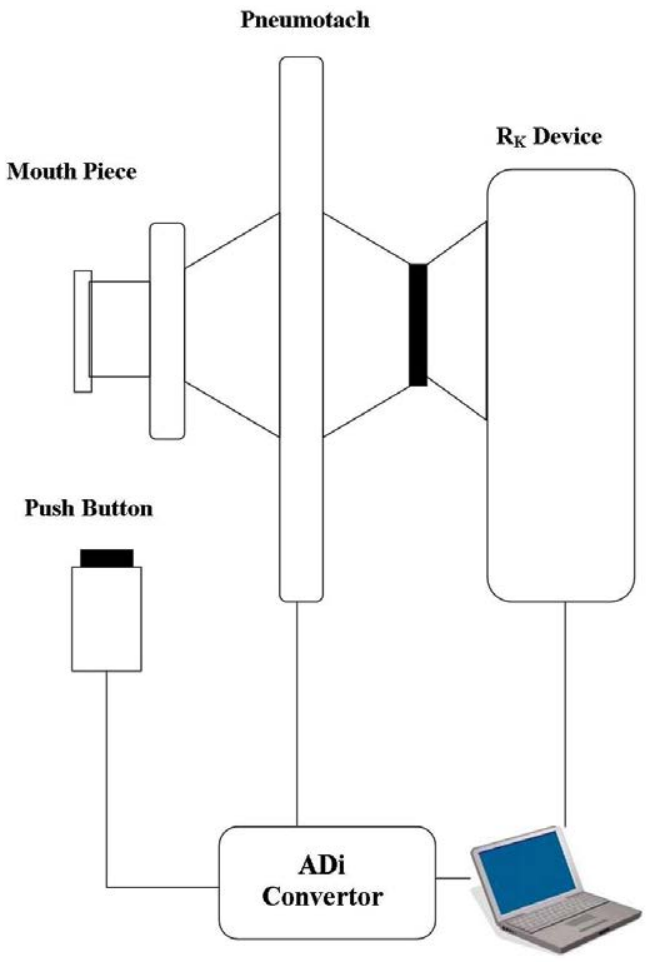

Figure 1: The experimental set-up 


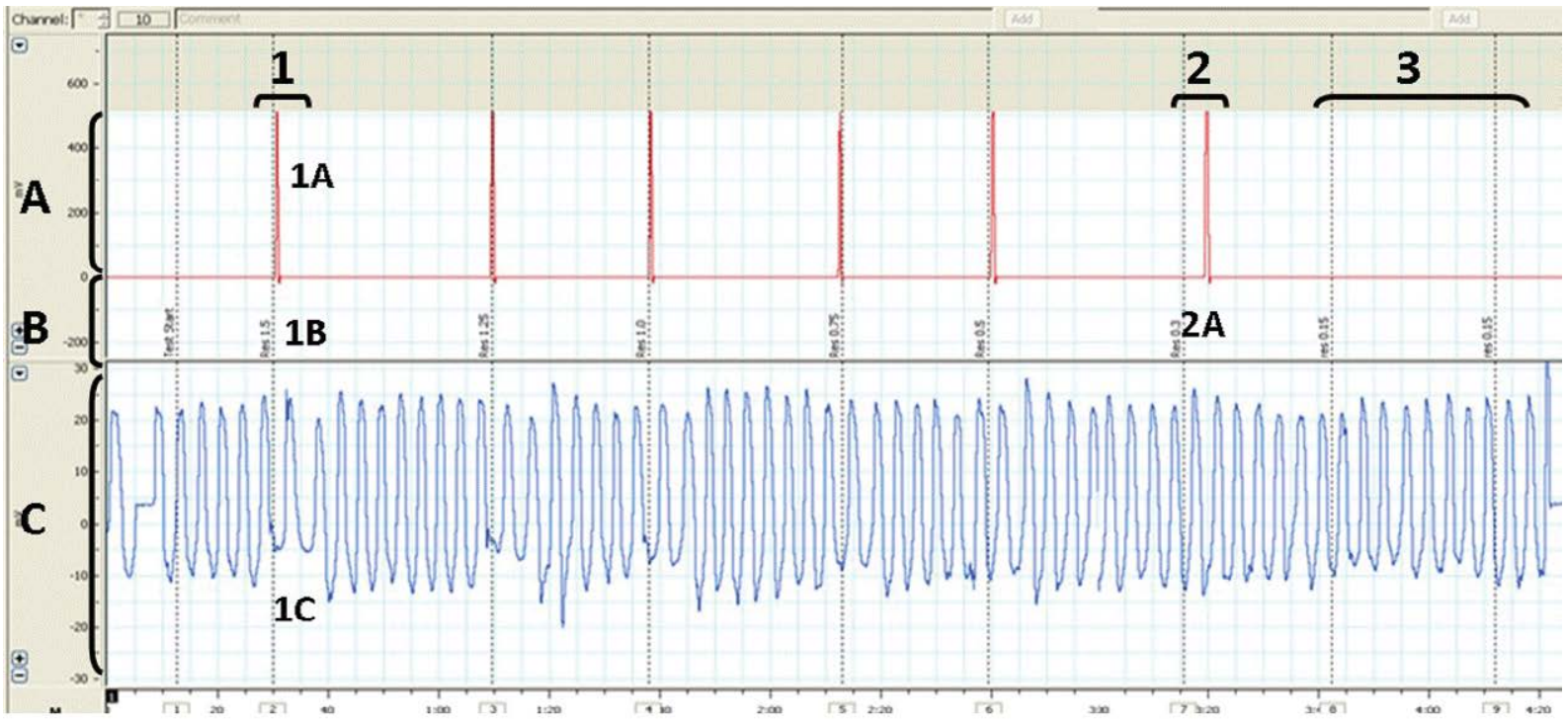

Figure 2: Computer output from a healthy participant undertaking a descending protcol trail (protocol $A$ ) with a $R_{K}$ load decreasing in magnitude from 1.5 to 0.15 $\mathrm{kPa}$.L.sec ${ }^{-1}$. Channel $\mathrm{A}=$ Participant responses to resistive load. Each spike represent the participant pushing the button in response to a perceived load applied. For $R_{K}$ loads 1.5 to $0.5 \mathrm{kPa}$.L.sec-1 the response is concurrent with onset of the $R_{\mathrm{K}}$ load being applied. Channel $B=T$ The electronic time 'stamps' inserted by the researcher as each load is applied indicating its onset and magnitude. This shows the different number of breaths between each loaded phase, used to prevent any temporal awareness of loading. Channel $\mathrm{C}=$ The participants respiratory flow during the trial. $1=S h o w s$ a resistance of $1.5 \mathrm{kPa}$. L.sec-1 being applied; the participants response (1A), the electronic time stamp made by the researcher (1B) and the effect on respiratory flow by the application of the $R_{K}$ load (1C). $2=S h o w s$ an $R_{K}$ load of $0.3 \mathrm{kPa}$.L.sec ${ }^{-1}$ being applied, showing a slightly delayed response by the participant $(2 \mathrm{~A})$ but this occurs during the 2 breath loaded cycle and is therefore included as an accurate response. $3=$ Shows an $R_{K}$ load of $0.15 \mathrm{kPa}$.L. $\sec ^{-1}$ being applied that is not detected by the participant.

\begin{tabular}{|c|c|c|c|c|}
\hline Loading Aspect & & & & \\
\hline $\begin{array}{c}\text { Number of breaths for which } \\
\text { load is applied }\end{array}$ & One $^{1}$ & $\mathrm{Two}^{2-5}$ & Five $^{6}$ & \\
\hline $\begin{array}{l}\text { Number of different loads used } \\
\text { and how often applied }\end{array}$ & 8 loads applied over three trials ${ }^{3}$ & $\begin{array}{c}5 \text { loads applied twenty five times } \\
\text { in a single trial }{ }^{1,2}\end{array}$ & 9 loads applied four times ${ }^{1}$ & $\begin{array}{c}\text { Two trials of } 9 \text { loads applied } \\
\text { three times }{ }^{1}\end{array}$ \\
\hline $\begin{array}{l}\text { Number of interspersed } \\
\text { unloaded breaths }\end{array}$ & $4-20^{3}$ & $3-6^{1,6}$ & $5-10^{4}$ & \\
\hline
\end{tabular}

${ }^{1}$ Davenport PW and Kifle Y [5], ${ }^{2} \mathrm{McQuiad}$ et al. [2], ${ }^{3}$ Wiley and Zachman [10], ${ }^{4}$ Puddy et al. [13], ${ }^{5}$ Bennet et al. [18], ${ }^{6}$ Fritz et al. [4].

Table 2: Different loading protocols reported in the literature.

\section{Data Analysis}

To score detection rates a similar method was used to that described by Wiley and Zechman [10], the percentage detection for trials was calculated by comparing the number of successful detections with the maximum possible. Statistical analysis and curve fitting was performed using statistical software (Sigmaplot V12.5, Systat, UK). Statistical significance was set at $\mathrm{p}<0.05$.

\section{Results}

Every participant was able to complete all sensitivity trials without any hesitation or difficulty.

In the healthy group a sigmoidal relationship between applied load and load detection was seen, the $50 \%$ detection rate was at an $\mathrm{R}_{\mathrm{K}}$ load of approximately $0.5 \mathrm{kPa} . \mathrm{L} \cdot \mathrm{sec}^{-1}$ for Protocol A (loads applied in descending order) and $0.6 \mathrm{kPa} \cdot \mathrm{L} \cdot \mathrm{sec}^{-1}$ for Protocol B (loads applied random order) (Figure 3 ). The most sensitive load detection range, between 80 and $20 \%$ detection was between 0.62 and $0.36(\Delta 0.26)$ and 0.73 and $0.45(\Delta 0.28) \mathrm{kPa} . \mathrm{L} \cdot \mathrm{sec}^{-1}$ for Protocol A and B respectively. There was no difference ( 1 WRM Anova, $p>0.05$ ) between the Protocols. The healthy group had good perceptual acuity and were able to detect loads as low as $0.25-0.3 \mathrm{kPa} \cdot \mathrm{L} \cdot \mathrm{sec}^{-1}$.

The responses in the chest disease group was different, and instead of a sigmoidal relationship they exhibited a threshold response, in which loads below $0.75 \mathrm{kPa} . \mathrm{L} \cdot \mathrm{sec}^{-1}$ were undetectable (Figure 4). Hence their perceptual ability was blunted.

\section{Repeatability}

In the repeatability trials (Healthy group only, Protocol C) when each $R_{K}$ was applied eight times, the load detection rate was $100 \%$ at 1 and $0.75 \mathrm{kPa} . \mathrm{L} \cdot \mathrm{sec}^{-1}$ but only $73 \%(8 / 11)$ and $36 \%(4 / 11)$ at 0.5 and 0.25 $\mathrm{kPa} . \mathrm{L} . \mathrm{sec}^{-1}$ respectively. In those participants who correctly detected a load, the load detection rate was similar to Protocol A falling from 100 to $8 \%$ between an RK load of 1 and $0.25 \mathrm{kPa} \cdot \mathrm{L}_{\mathrm{sec}} \mathrm{se}^{-1}$ (Figure 5).

\section{Discussion}

A novel system to detect perceptual sensitivity to resistive loads is shown. All sixteen participants were able to complete all sensitivity trials $(n=85)$ with minimal training. While mental cooperation was required in terms of concentration the trials themselves required little physical effort. Repeatability of detection of resistive loads was good $(>90 \%)$ in the healthy group when the RK Load was over 0.75 $\mathrm{kPa} \cdot \mathrm{L} \cdot \mathrm{sec}^{-1}$ however there was a loss of perceptual ability with lower $\mathrm{R}_{\mathrm{K}}$ loads. The healthy group showed a graded decline in ability to detect loads in protocols A and B. The order in which the resistances were applied made no difference to the load detection rates. The chest disease group were unable to detect $\mathrm{R}_{\mathrm{K}}$ loads below $0.75 \mathrm{kPa}$.L.sec ${ }^{-1}$.

This system has benefits over the other methods described as it easier to match the applied load to the response by a participant. This 


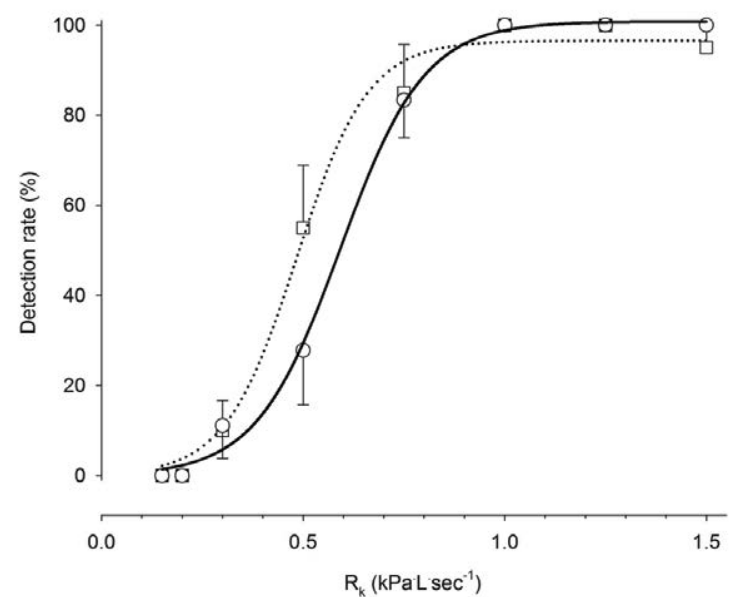

Figure 3: Load detection in healthy group (mean $\pm S E M, n=10$ ) of $R_{K}$ during protocol $A(\square)$ and $B(\circ)$. Using non-linear regression a sigmoidal function $y=a /\left(1+e^{\wedge}(-((X-X \quad 0) / b))\right)$ was applied to each protocol, $A: a=96.5, b=0.088$, $\mathrm{X} 0=0.49, \mathrm{r} 2=0.99, \mathrm{p}<0.0001$, protocol, $\mathrm{B}: \mathrm{a}=100.85, \mathrm{~b}=0.104, \mathrm{X} 0=0.59$ $r^{2}=0.99, p<0.0001$. No significant differences were found between protocol $A$ and $B, p>0.05$.

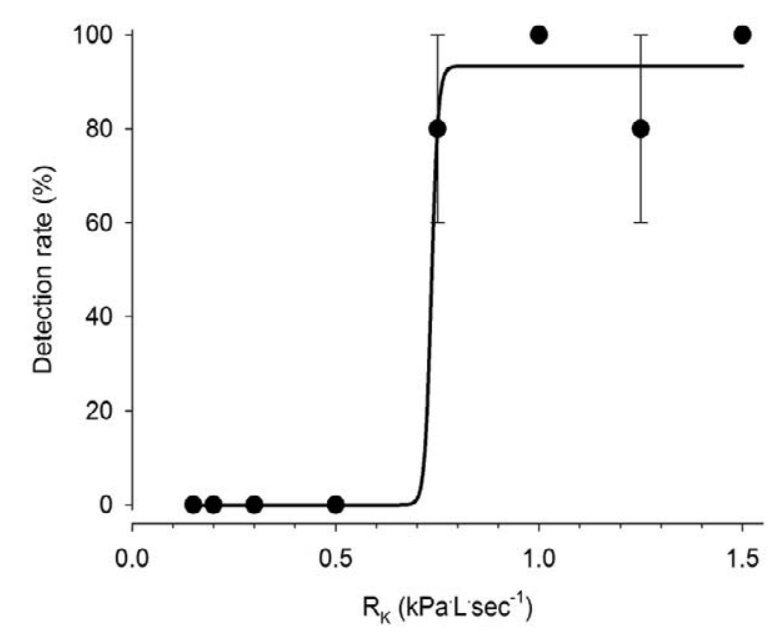

Figure 4: Load detection in the chest disease group (mean \pm SEM, $n=5$ ) of $R_{K}$ during protocol $A$. A line of best fit was applied (see Figure 3 ): $a=100, b=-$ $0.064, X 0=-0.68, r^{2}=0.98, p<0.0001$.

allows the level and duration of the resistive load to be easily adapted in a manner that avoids alerting the trial participant; and using a resistive load that is independent of airflow $[14,15]$.

In the healthy group both protocol $\mathrm{A}$ and $\mathrm{B}$ showed a similar decline in detection rates with lower $\mathrm{R}_{\mathrm{K}}$ loads. This would suggest that this method could be used to evaluate the level of load sensitivity in these individuals. The decline in the mid-range of $R_{K}$ loads were similar for both protocols, when the RK was decreased sequentially (Protocol A) or in a random order (Protocol B), suggesting that participants can detect a load irrespective of the previous load. Sequentially descending protocols are often used in other physiological tests such as those used by the British Audiological Society [12], they are easier to apply and a test can be terminated once a threshold has been reached.

In the chest disease group a cut-off response is apparent with an inability to detect $\mathrm{R}_{\mathrm{K}}$ loads below $0.75 \mathrm{kPa} . \mathrm{L} \cdot \mathrm{sec}^{-1}$. In pulmonary conditions characterised by airflow limitation such as COPD and asthma, the intrinsic resistive loading is already increased [16], so any extrathoracic load lower than this intrinsic load will not be detectable. It is however unclear if there is some remnant of the sigmoidal response seen in the healthy lung and future work would benefit from looking at more loads between 0.8 and $0.4 \mathrm{kPa} .1 . \mathrm{sec}^{-1}$. This group had a high median MRC Dyspnoea score of 4 which suggests that Protocol A could be used to quantify the sensation of breathlessness separately from than load detection. Pulmonary rehabilitation programmes would benefit from such a measurement as any reductions in dysponea perceived or physiological would benefit patients [17].

The methodologies of previous studies were used to inform the development of the protocol in this study. However where this significantly differs is in the magnitude of the resistive loads applied. Wiley \& Zechman [10] applied eight loads between 0.02 to $18 \mathrm{kPa}$ (0.2-1.8 $\left.\mathrm{cm} \mathrm{H}_{2} 0\right)$, Fritz et al. [4] applied loads ranging from 0.02-0.78 $\mathrm{kPa}\left(0.25-8 \mathrm{~cm} \mathrm{H}_{2} \mathrm{O}\right)$, whereas McQuaid et al. [2] applied a percentage $(20,60,100,140,180 \%)$ of the participant's measured baseline airway resistance, REFF. When a constant resistance is applied rather than a flow rate dependent value as is the case with the $R_{K}$ device then greater loads are needed, for example between 0.25-1.5 kPa.L.sec ${ }^{-1}$ (Figures 3 and 4 ). The difference with these previous studies, is most probably due to the use of flow dependent loads used.

In conclusion, this technique shows that perceptual acuity manifest as load detection sensitivity differs in people with chest disease. In the presence of chest disease load detection exhibited a threshold-type response with no loads detectable below $0.75 \mathrm{kPa} . \mathrm{L} \cdot \mathrm{sec}^{-1}$. While in those with healthy lungs there was a sigmoidal load detection response and a minimal detection of between 0.25 to $0.3 \mathrm{kPa} \cdot \mathrm{L} \cdot \mathrm{sec}^{-1}$.

\section{Author Contributions}

TP designed and conducted the study. TP and EMW wrote, compiled and reviewed the manuscript.

\section{Conflict of Interest}

A PhD bursary for TP was provided by MicroMedical UK. The funder had no role in study design, data collection and analysis, decision to publish, or the preparation of this manuscript. The authors delclare no conflict of interest.

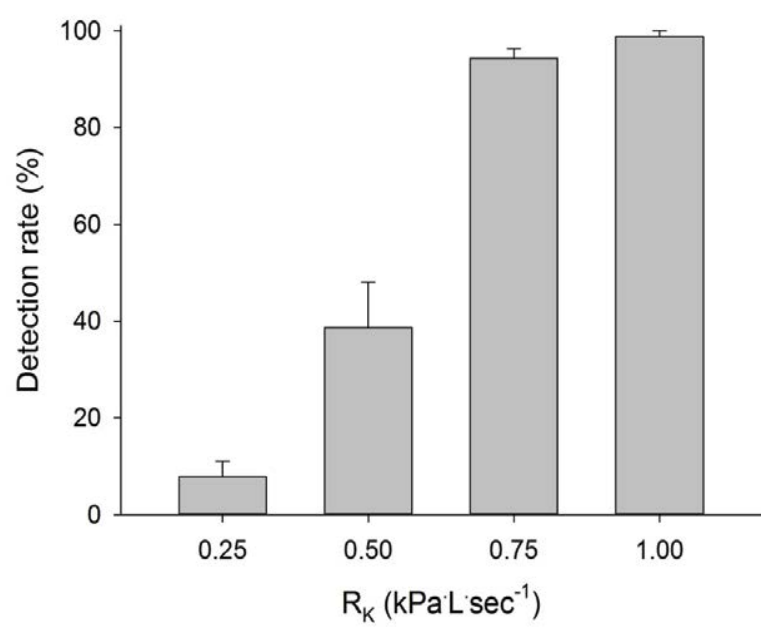

Figure 5: Load detection in healthy group (Mean \pm SEM, $n=11$ ) of RK during protocol C. 


\section{Ethics}

This study was approved by the South East Wales NHS Research Ethics Committee (Rec No 09/WSE02/17) for patients and the Faculty Research Ethics committee for the patients and control participants.

\section{Authorship and Contributorship}

This manuscript was drafted and finalised by Tom Powell and E Mark Williams

\section{References}

1. Stenton C (2008) The MRC breathlessness scale. Occup Med (Lond) 58: 226-227.

2. McQuaid EL, Fritz GK, Yeung A, Biros PA, Mansell A (1996) Resistive-load detection in healthy school-aged children. Pediatr Pulmonol 22: 357-363.

3. Jefferies A and Turley A (1999) Respiratory System. Mosby. Spain

4. Fritz GK, McQuaid EL, Nassau JH, Klein RB, Mansell A (1999) Thresholds of resistive load detection in children with asthma. Pediatr Pulmonol 28: 271-276.

5. Davenport PW, Kifle $Y(2001)$ Inspiratory resistive load detection in children with life-threatening asthma. Pediatr Pulmonol 32: 44-48.

6. Fletcher CM, Elmes PC, Fairbairn AS, Wood CH (1959) The significance of respiratory symptoms and the diagnosis of chronic bronchitis in a working population. Br Med J 2: 257-266.

7. [No authors listed] (1999) Dyspnea. Mechanisms, assessment, and management: a consensus statement. American Thoracic Society. Am J Respir Crit Care Med 159: 321-340.
8. Nishimura K, Izumi T, Tsukino M, Oga T (2002) Dyspnea is a better predictor of 5-year survival than airway obstruction in patients with COPD. Chest 121: 1434-1440.

9. Bestall C, Paul EA, Garrod R, Garnham R, Jones PW, et al. (1995) Usefulness of the Medical Research Council (MRC) dyspnoea scale as a measure of disability in patients with chronic obstructive pulmonary disease. Thorax 54 : 581-586.

10. Wiley RL, Zechman FW Jr (1966) Perception of added airflow resistance in humans. Respir Physiol 2: 73-87.

11. Powell T, Williams EM (2012) Effect of resistive load on the inspiratory work and power of breathing during exertion. PLoS One 7: e49681.

12. British Society for Audiology (2004) Pure tone air and bone conduction threshold audiometry with and without masking and determination of uncomfortable loudness levels.

13. Puddy A, Giesbrecht G, Sanii R, Younes M (1992) Mechanism of detection of resistive loads in conscious humans. J Appl Physiol (1985) 72: 2267-2270.

14. Allen SC, Vassallo M, Khattab A (2009) The threshold for sensing airflow resistance during tidal breathing rises in old age: implications for elderly patients with obstructive airways diseases. Age Ageing 38: 548-552.

15. Allen SC, Khattab A (2012) The airflow resistance sensing threshold during tidal breathing rises in old age in patients with asthma. Age Ageing 41: 557-560.

16. Hill K, Eastwood P (2011) Effects of loading on upper airway and respiratory pump muscle motoneurons. Respir Physiol Neurobiol 179: 64-70.

17. Wadell K, Webb KA, Preston ME, Amornputtisathaporn N, Samis L, et al (2013) Impact of pulmonary rehabilitation on the major dimensions of dyspnea in COPD. COPD 10: 425-435. 